\title{
SECURITIZACIÓN, SELECCIÓN Y EXCLUSIÓN: EL PAPEL DE LA LEY DE MigRACIÓN DE 2011 COMO "MURO LEGAL" CONTRA LA MigRACIÓN DESDE MÉXICO Y CENTROAMÉRICA
}

\author{
Securitization, Selection and Exclusion: The Role of \\ the MeXican Immigration Bill of 2011 as a "Legal Wall" \\ against Migration from México and Central America
}

\author{
Luis González Placencia* \\ Laura Díaz de León Fernández de Castro*** \\ doi: https://doi.org/10.31644/ED.V8.N2.2021.A08
}

Resumen: La securitización de la política migratoria mexicana ha sido analizada como efecto del endurecimiento de las políticas que para la seguridad interior implementó el gobierno de los Estados Unidos después de los atentados del 11 de septiembre de 2001. A la luz de un análisis crítico que combina las perspectivas de securitización como "gobierno de las migraciones" y como producción de excepción para la "exclusión del migrante", este artículo problematiza esa posición y propone entender el proceso securitizante como un mecanismo en el que "selección” y "exclusión" operan de forma complementaria para garantizar la presencia de mano de obra indocumentada en las economías centrales y, al mismo tiempo, servir al propósito del enclaustramiento preventivo del norte global. Para estos fines, analizamos el papel del marco constitucional de derechos humanos de las personas migrantes en México como función de administración de la movilidad humana y el contexto de violencia que se vive en el territorio nacional mexicano como el lugar en el que se actualiza la excepción.

Palabras clave: legislación secundaria sobre migración en México, procesos selectivos de migración, gestión securitaria de la migración, espacios de excepcionalidad de los derechos humanos de migrantes.

\footnotetext{
* Dr. en Política Criminal, profesor investigador Titular B del Centro de Investigaciones Jurídico Políticas de la Universidad Autónoma de Tlaxcala, México, y líder del cuerpo académico. Correo-e: lgp@uatx.mx.

** Directora Ejecutiva del Instituto para la Seguridad y la Democracia A.C., Lic. en Psicología, estudiante de la Maestría Interinstitucional en Derechos Humanos de la Universidad Autónoma de Tlaxcala, México. Correo-e: diazdeleon@insyde.org.mx.

Fecha de recepción: 15/02/2020. Fecha de aceptación: 24/05/2021. Fecha de publicación: 30/07/2021.

\section{(c)) BY-NC-ND}

EntreDiversidades. Revista de Ciencias Sociales y Humanidades, Vol. 8, Núm. 2 (17), julio-diciembre 2021. Páginas: 167-190 ISSN-e: 2007-7610. https://doi.org/10.31644/ED.V8.N2.2021.A08
} 
Abstract: The securitization of Mexican immigration policy has been analyzed as an effect of the hardening of policies for internal security that the United States government implemented after the attacks of September 11, 2001. In the light of a critical analysis that combines the perspectives of securitization as the "government of migration" and as an exception production for the "exclusion of the migrant", this article problematizes this position and proposes to understand the securitization process as a mechanism in which "selection" and "exclusion" operate in a complementary way to guarantee the presence of undocumented labor in the central economies and at the same time, to serve the aim of the preventive lockdown of the global North. For these purposes, we analyze the role of the constitutional human rights framework of migration in Mexico as a function of human mobility administration and the context of violence that exists in the Mexican national territory as the place in which the exception is updated.

Keywords: secondary legislation on migration in Mexico, selective migration processes, security management of migration, spaces of exceptionality of the human rights of migrants.

\section{Introducción}

El fenómeno migratorio constituye uno de los temas más delicados en la agenda internacional mexicana, fundamentalmente desde que a mediados del siglo XIX la dependencia estadounidense de mano de obra barata hizo de la frontera norte mexicana un filtro que desde entonces y hasta ahora ha funcionado como un dispositivo legal e ilegal para el ingreso de connacionales a los mercados laborales, igualmente legales e ilegales, de los Estados Unidos (Chomsky, A., 2014).

Como lo señala Durand (2000), en la relación entre ambos países el asunto migratorio ha sido históricamente problemático. Sin embargo, desde la década de los ochenta del siglo pasado por lo menos, la precarización de la vida, los fenómenos naturales y el aumento de la violencia estructural en los países situados al sur de la frontera mexicana actuaron como factores de desplazamiento en las poblaciones centroamericanas, especialmente de Guatemala, Honduras y El Salvador, lo que no solamente extendió hasta esas latitudes el origen de los flujos migratorios hacia Norteamérica (Fernández, 2012; Sandoval, 2015), sino que, en el contexto de las nuevas amenazas percibidas por los gobiernos estadounidenses luego de los atentados del 11 de septiembre de 2001 (en adelante 11s), incrementó la presión para que el Estado mexicano ahora se ocupara, además de las y los mexicanos que cruzan sin documentos hacia los Estados Unidos, también de quienes desde Centroamérica ingresan a territorio mexicano por la frontera sur (Schiavon y Velázquez, 2007). ${ }^{1}$

Muy a pesar de que en la última década México ha realizado importantes reformas a nivel constitucional que se dirigen al respeto, protección y promoción de los derechos humanos (García-Ramírez y Morales, 2011; Carbonell, 2014), incluidos, por supuesto, los de las personas

\footnotetext{
${ }^{1}$ Un panorama general bastante detallado de la situación de los flujos migratorios en la región centroamericana y mexicana puede hallarse en Canales y Rojas (2017). En su estudio se puede profundizar en el análisis de los factores que impulsan la migración —económicos, demográficos, pobreza, crisis humanitarias y cambio climático—, así como en las relaciones con la trata y el tráfico ilícito de migrantes, las apuestas normativas de los estados y la participación de las Organizaciones de la Sociedad Civil en los intentos por construir soluciones.
}

EntreDiversidades. Revista de Ciencias Sociales y Humanidades, Vol. 8, Núm. 2 (17), julio-diciembre 2021. Páginas: 167-190 ISSN-e: 2007-7610. https://doi.org/10.31644/ED.V8.N2.2021.A08 
migrantes, lo cierto es que estas reformas, que contienen sin duda un alto contenido simbólico, distan mucho de representar una realidad que, por el contrario, se muestra notoriamente violenta y por ello completamente lejana al orden constitucional (Guevara, 2014). Naturalmente, esa violencia es evidente en el nivel estructural y en las estadísticas de víctimas de violaciones graves a los derechos humanos, pero también se muestra en las propias leyes, en las políticas institucionales y, sobre todo, en las prácticas que cotidianamente realizan las y los agentes del Estado mexicano.

Aunque, como demuestra Guevara (2014), las relaciones entre migración y seguridad no son recientes, es en el contexto del proceso de "securitización" que se ha venido construyendo por lo menos en los últimos cuarenta años en Europa y en los Estados Unidos, en el que ha cobrado su significación actual. Bajo esta premisa, es nuestro interés discutir en este texto cómo en México la securitización funciona como una tecnología de gobierno sobre la migración indocumentada y, al mismo tiempo, como un mecanismo productor de excepción, útil a los fines de expulsión y eliminación de la "amenaza migrante". Este objetivo intenta responder a la pregunta acerca del rol que el marco normativo — y en especial la Ley de Migración de 2011— juega, como un "muro legal" que resulta funcional a los procesos de selección y exclusión de las personas migrantes que intentan cruzar por México hacia los Estados Unidos. Para ello, planteamos inicialmente qué entendemos por securitización, a la luz del debate teórico que existe hoy día en el país sobre el tema; enseguida mostramos como la legislación secundaria en la materia junto a otros dispositivos tecnológicos funcionan para el propósito de la gestión securitaria y, finalmente, argumentamos que el contexto de anomia y violencia que caracteriza partes importantes del suelo nacional ha sido funcional a la construcción del territorio mexicano como zona de excepción, destinada al destierro de las personas migrantes. Sostenemos que, en este marco, el discurso de los derechos humanos no solo queda relativizado, sino que resulta funcional tanto a los fines de la administración de la movilidad humana como al de la contención de las personas migrantes no documetadas.

\section{Encuadre teórico: ¿qué significa "securitizar"?}

Como es sabido, el concepto de "securitización" se enmarca en la teoría del mismo nombre propuesta por los teóricos de la llamada Escuela de estudios críticos sobre seguridad de Copenhague (Orozco, 2006; Campesi, 2012; Moreno, 2021), quienes problematizaron las perspectivas más tradicionales sobre la seguridad nacional — concebidas dentro del llamado realismo, en el campo de las relaciones internacionales - como respuesta a amenazas concretas, externas, especialmente militares, provenientes de un país y enderezadas contra otro país y por ello vinculadas a la defensa de las soberanías nacionales (Rangel, 2007). Para los teóricos escandinavos, esta concepción resultaba demasiado rígida y no permitía entender las reacciones a otro tipo de amenazas, más bien abstractas y no necesariamente externas. Estas discusiones fueron dando forma a las políticas de seguridad que comenzaron a aplicarse desde los años 90 en occidente (Buzan, Weaver y De Wilde, 1998). En el marco del constructivismo social, estos autores definieron como securitización al proceso lingüístico que al revelar la importancia de un asunto al punto de considerarle una amenaza para "[...] la supervivencia de un ente, ya sean individuos o conglomerados" (Orozco, 2006: 145 n.) lo torna un tema de seguridad. En efecto, como explica Moreno:

EntreDiversidades. Revista de Ciencias Sociales y Humanidades, Vol. 8, Núm. 2 (17), julio-diciembre 2021. Páginas: 167-190 ISSN-e: 2007-7610. https://doi.org/10.31644/ED.V8.N2.2021.A08 
Señalar un asunto como una amenaza potencial para la seguridad supone la adopción de medidas que en situaciones normales no se tomarían para hacerle frente. De esta manera se anula todo el engranaje democrático y el debate que debe caracterizar una toma de decisión y, apelando al miedo y a la supervivencia, se entra en una esfera en la que todo está permitido más allá de lo establecido legal o constitucionalmente (2021:15).

Más allá de las consecuencias del fenómeno que describe, las posibilidades de aproximación radican en el énfasis puesto en la dimensión de la definición del propio concepto como un problema que se construye a través del discurso de determinados actores sociales y de las percepciones que produce en el público, con independencia de que exista una realidad objetiva que lo justifique, pero que termina manifestándose en normas, políticas y prácticas que finalmente le sirven de legitimación. ${ }^{2}$ Así, una vez instalado en el imaginario social como una amenaza, lo securitizado es susceptible de ser combatido en aras de la protección subjetiva contra el temor y para tranquilizar los más primarios impulsos de supervivencia.

En el ámbito de los estudios sobre migración, el enfoque de la securitización de la política migratoria comenzó a adoptarse en México desde principios del actual siglo y especialmente luego de los ataques que en territorio estadounidense perpetró Al-Qaeda en 2001. Más recientemente, esta perspectiva ha dado lugar a una discusión que, por una parte, identifica en la mayoría de las y los autores la certeza de que el país ha securitizado sus medidas migratorias como efecto directo del giro operado en la política de seguridad interior (Homeland Security) de los Estados Unidos después del 11s (Armijo, 2011; Benítez, 2011; Correa, 2014; Hernández, 2018; Calleros, 2010, inter alia); por la otra parte, autores como Trevińo (2016 y 2020) o Guevara (2014) ponen en duda esta posición. Para Trevińo, no se cumplen las condiciones que la teoría de la securitización de los daneses plantea para considerar que, en efecto, un proceso así haya tenido lugar en México y que, al recurrir a la securitización como "la respuesta que lo explica todo", se pierde de vista la posibilidad de entender la tragedia humanitaria que se vive en el país desde "otras explicaciones más elaboradas" (2016: 263; 283-284).

Guevara, por su parte, afirma que la práctica de detención administrativa de personas migrantes se remonta a la Ley General de Población de 1974 y que por ello no es posible afirmar que esta haya iniciado o profundizado luego del 11s; de hecho, concluye, los vínculos entre seguridad y migración obedecen a:

\footnotetext{
${ }^{2}$ En el campo de las ciencias sociales y en especial de la criminología esta posición es remisible al clásico trabajo de Peter Berger y Thomas Luckmann (2003) publicado en 1966, cuyos postulados afirman que la realidad, incluidos los llamados fenómenos sociales, es socialmente construida y que, en razón de ello, su análisis debe realizarse desde los procesos que la producen. Desde el punto de vista epistemológico esta posición procede del idealismo y de la fenomenología, lo que le hace inconmensurable en relación con el realismo, cuyos antecedentes epistemológicos se ubican en el objetivismo y en el positivismo.
}

EntreDiversidades. Revista de Ciencias Sociales y Humanidades, Vol. 8, Núm. 2 (17), julio-diciembre 2021. Páginas: 167-190 ISSN-e: 2007-7610. https://doi.org/10.31644/ED.V8.N2.2021.A08 
[...] un proceso que viene arrastrando el país desde su independencia, en donde se mezclan argumentos relacionados con una supuesta protección a la economía (seleccionar y admitir), a la salud (evitar que ingresen personas no nacionales enfermas física o mentalmente) y a la seguridad (impedir el ingreso o permanencia de aquellas personas que hayan cometido un delito o sean consideradas una amenaza para la seguridad nacional) (2014: 116).

Sin embargo, y no obstante la aparente novedad del tema, lo cierto es que el fenómeno de la securitización ha sido tratado desde la década de los noventa por la criminología crítica cuando varios de sus teóricos identificaron transformaciones en los procesos de criminalización que poco a poco fueron atribuyéndose a la nueva relación de supraordinación entre las esferas del Estado y del mercado, a favor de esta última (Melossi, 1997; Pavarini, 1997; Monclús, 2005; Delgado, 2006; Zino, 2006; Anitua, 2006; González y Gluyas, 2006). En sus análisis, esa transformación dio lugar a un cambio que modificó la idea de peligro concreto, simbolizado por el delincuente convencional, hacia la de riesgo — posible—, representado por figuras de peligro abstracto construidas en categorías "potencialmente" nocivas que antes de causar daños objetivos, y de hecho con independencia de hacerlo o no, producen temor en quienes se van construyendo como un "nosotros", igualmente abstracto, que, en tanto víctimas "potenciales", terminan legitimando acciones preventivas, de eliminación, contención o expulsión de esas identidades portadoras del riesgo (González, 2001). Entre estas figuras de peligro abstracto la criminología crítica identificó desde entonces a los narcotráficantes, a los terroristas y a las personas migrantes. ${ }^{3}$

En la nueva correlación de fuerzas característica del neoliberalismo, al Estado le corresponde brindar las condiciones para facilitar la privatización de las relaciones sociales y el aseguramiento (securitización) de los riesgos que puedan afectar esos procesos: el común denominador entre las nuevas amenazas para la estabilidad de los mercados en la era neoliberal es la condición que en términos de empresa poseen narcotráfico, terrorismo y migración, posibles precisamente porque se alimentan de mercados legales (armas, precursores, mano de obra). En ese sentido es que "securitizar" se traduce en una operación más compleja que funciona más bien como un mecanismo de selección que por una parte permite elegir entre lo que entra y lo que queda fuera, o bien entre lo que puede permanecer y lo que debe ser expulsado, lo que debe ser puesto "a-bando", en términos de Nancy (1983): "abandonado" allende el límite de la ley. Por la otra, define el afuera de la ley, un "no-lugar" donde no rige la regla, sino la excepción (Agamben, 2003) y, en tercer lugar, construye a las identidades consideradas amenazantes como homines sacri que, como afirma el propio Agamben (1998), son seres cuyas vidas pueden ser matadas impunemente porque su muerte constituye el acto sacrificial que afianza la estabilidad y el orden de la gubernamentalidad neoliberal.

\footnotetext{
${ }^{3}$ Campesi (2012) propone que, en este marco, pueden identificarse tres aproximaciones desde las cuales la migración ha sido construida como una amenaza: 1) los migrantes son responsabilizados del incremento en la delincuencia común y por ello son considerados como una amenaza potencial al porden público; 2) los migrantes no se asimilan y por tanto amenazan la integridad identitaria y cultural doméstica; y 3) los migrantes son competidores desleales en el mercado laboral porque abaratan el costo de la mano de obra y usufructúan servicios sociales que deberían ser preferentemente para los locales.
}

EntreDiversidades. Revista de Ciencias Sociales y Humanidades, Vol. 8, Núm. 2 (17), julio-diciembre 2021. Páginas: 167-190 ISSN-e: 2007-7610. https://doi.org/10.31644/ED.V8.N2.2021.A08 
Así entendida, la securitización ha sido condición para la paulatina concreción de un proceso de mayores dimensiones que bien podría identificarse como el enclaustramiento de occidente en lo que se ha dado en llamar el "norte global". Es nuestra tesis, por tanto, que la securitización sirve al propósito de construir una separación física, psicológica, política, legal y cultural respecto de lo que se identifica entonces como el "sur global" que en la dialéctica de la dependencia norte-sur es relegado a la condición de zona de excepción. ${ }^{4}$ Sin embargo, consideramos que esa separación no lo es tout court, sino que es más bien porosa, lo suficiente para admitir el intercambio de materias primas — incluida la mano de obra indocumentada — de sur a norte y de manufacturas —incluidas, por ejemplo, las armas - de norte a sur, y que es sobre esa porosidad que opera la securitización como tecnología útil a la distinción entre los tráficos legales de los ilegales. Pero reconocemos, asimismo, que en ese proceso la separación también es útil a los fines de la construcción, definición, detección y contención de aquello que es considerado una amenaza. ${ }^{5}$

Es en esta perspectiva donde cabe el mérito de los teóricos escandinavos al definir la securitización como la intención de otorgar a un determinado fenómeno una importancia tal que lo revela como amenaza para la estabilidad de la vida y la tranquilidad — del norte global— y que por ello justifica un tratamiento de excepción, allende los recursos que legalmente serían permitidos en una situación regular. Como afirma Campesi:

Esta noción representa un desplazamiento en relación con una comprensión de la seguridad centrada en el Estado, en la medida en que en el núcleo de reflexión ya no están situados la integridad de la soberanía política o el mantenimiento del orden público interno, sino la supervivencia de la sociedad y, por lo tanto, el mantenimiento de sus características identitarias, económicas y sociales básicas (2012: 6).

\footnotetext{
${ }^{4}$ Materialmente, han sido México para los Estados Unidos y Marruecos para la Unión Europea los países que simbólicamente conforman la frontera entre el norte y el sur global (Ríos, 2015).

${ }^{5}$ Como es sabido, la metáfora norte-sur se ha empleado para representar la contradicción entre los países ricos, normalmente ubicados en el norte geográfico, y los más pobres, geográficamente situados en el sur; sin embargo, no debe tomarse literal porque en la mayoría de los países estas diferencias existen configurando dentro de cada uno sus propias zonas de privilegio y de exclusión. Así como existen poblaciones depauperadas que habitan las zonas de abandono en los países industrializados, correlativamente en el sur geográfico existen zonas de privilegio de interés global como es el caso de los enclaves turísticos, los energéticos y algunos enclaves habitacionales, en los que la securitización también ha constituido no solamente un recurso de protección sino, por ende, de aislamiento. Esta es una consecuencia del paulatino alejamiento entre los que más y los que menos tienen que, a jucio de Harvey (2007), Chomsky, N. (2017) y Brown (2016), entre otros, es producto de la racionalidad neoliberal. Así, en el norte geográfico hay zonas que forman parte del "sur global" y en el sur geográfico hay enclaves que forman parte del "norte gobal". No obstante, debe entenderse que este aislamiento no es total ni absoluto, es poroso, lo que significa que se deja pasar hacia las zonas de privilegio lo que es conveniente para la subsistencia de su modus vivendi, trátese de personas o bienes (en ello consiste la selección), y detiene aquellas — personas o bienes— que no lo son (acción que correpsonde a la exclusión). Sobre este proceso, ver González y Díaz de León (2020).
}

EntreDiversidades. Revista de Ciencias Sociales y Humanidades, Vol. 8, Núm. 2 (17), julio-diciembre 2021. Páginas: 167-190 ISSN-e: 2007-7610. https://doi.org/10.31644/ED.V8.N2.2021.A08 
Y es aquí, justamente, donde se hace necesario ir más allá. Primero, porque en el contexto de la construcción de la frontera global entre el norte y el sur, asegurar (securitizar) implica, entonces, no tanto identificar algo, sino más bien a alguien, construido como potencialmente amenazante para la vida o la tranquilidad de aquel "nosotros" - habitante del norte global y por eso potencial víctima- En este sentido, securitizar es "ilegalizar" al migrante indocumentado, lo que supone colocarle en el ámbito de interés de lo legal y, por tanto, en el de la seguridad (Guild, citado en Campesi, 2012); implica, entonces, visibilizar su condición clandestina - evidenciarle como "polizón" - y con ello identificarle, como dice Campesi, con otras identidades clandestinas transnacionales atrayendo a "su órbita un conjunto de discursos securitarios [...] que están al centro del proceso de estructuración del campo de la política transnacional de seguridad, en la que militares y fuerzas policiales tienden a compartir objetivos e instrumentos, mezclándose de forma creciente" (Bigo, citado en Campesi, 2012: 8).

Segundo, porque esas zonas de excepción son al mismo tiempo un espacio y una situación, lo que explica que la excepción es también un estigma que se porta en la propia definición de securitizado - como criminal, como ilegal o como indocumentado-, y que determina grupos de personas que, como lo ha planteado Mbembe (2011), constituyen una especie de "cuarto mundo" que habita —-para servir, añadimos - dentro de las economías centrales. ${ }^{6} \mathrm{Y}$ tercero, porque la especificidad del caso mexicano apunta trágicamente a un futuro en el que, como ahora acontece en el territorio de esta nación, la excepcionalidad se extiende como condición para la privatización de las violencias y para la mundialización de la intemperie hacia todo el sur global.

Desde una perspectiva geográfica, el territorio mexicano se ha convertido en los últimos treinta o cuarenta años en una región de excepción, la primera zona de intemperie que se dibuja como la frontera sur del norte global. ${ }^{7}$ Pero también, y al mismo tiempo, desde una perspectiva más bien fisiológica, ha sido el núcleo de operación de todo un despliegue burocrático donde leyes, reglamentos, políticas y prácticas, normativamente atribuidas a autoridades militares, administrativas y policiales, funcionan como mecanismos de selección que hacen de la totalidad del territorio y no solo de la línea fronteriza una gran aduana donde se decide quiénes entran y

\footnotetext{
${ }^{6}$ Esta idea sugiere una complejidad mayor que puede ser comprendida desde el análisis que Frantz Fanon (1973 [1952]) hace de la negritud como una marca que se porta en la piel y que hace visible el lugar subordinado que los blancos asignan a los negros a pesar de las "máscaras blancas" que representan su asimilación a la cultura occidental. El proceso que va de estar preso o no tener documentos al de ser delincuente o ser indocumentado representa la imposición del estigma que condena a las personas así significadas a la excepción: la llevan consigo, la portan en su inucursión por los espacios de la legalidad. Desde otra perspectiva, la de Agamben (1998), este proceso representa el desnudamiento de estas personas, la reducción del bios al zoe o vida nuda, que les construye como homo sacer.

${ }^{7}$ La "excepción" es el espacio donde no rige el estado de derecho. Es un lugar sin ley, o donde la ley no es la que está escrita en las normas, sino en la voluntad de quien tiene el poder, que actúa con plena impunidad a favor de sus intereses. Como dice Agamben (1998), se trata del espacio donde la excepción se ha hecho norma. Paradójicamente, ese espacio de excepción está fijado por la ley, fuera de cuyos contornos es que se manifiesta. Usamos este concepto para señalar dos circunstancias: 1) que en el territorio mexicano el marco legal migratorio tiene un valor simbólico que expresa intereses globales y no el interés público que debería representar, y 2) que, en razón de ello, las personas migrantes quedan ubicadas en ese espacio en situación de desprotección, de desamparo y a merced de los poderes fácticos. La zona de excepción es una zona de abandono donde quien está situado ahí carece de protección.
}

EntreDiversidades. Revista de Ciencias Sociales y Humanidades, Vol. 8, Núm. 2 (17), julio-diciembre 2021. Páginas: 167-190 ISSN-e: 2007-7610. https://doi.org/10.31644/ED.V8.N2.2021.A08 
quiénes no a suelo estadounidense. ${ }^{8}$ Una "frontera vertical" (Casillas, 2008; Varela, 2019) que, con casi dos millones de kilómetros cuadrados, salvaguarda en América la tranquilidad del norte global. ${ }^{9}$

\section{La securitización legal de la migración: derechos sin garantías}

Una de las aparentes inconsistencias que se señalan como crítica a la aplicación de la teoría de la securitización al caso mexicano radica precisamente en que no hay un discurso abierto anti inmigrantes que se articule desde el gobierno, el empresariado o las élites, sino que más bien —desde el controvertido Plan Sur (Casillas, 2002) en el sexenio de Vicente Fox hasta las más recientes declaraciones en el actual gobierno de López Obrador - la intención declarada de defender los derechos humanos o de ver el tema desde la perspectiva de la seguridad humana parece ser el marco de justificación de las reformas, planes y programas que en la materia México ha implementado en ese arco de tiempo (Treviño, 2016 y 2020).

Sin embargo, de acuerdo con el encuadre teórico planteado, es justamente la explicitación de ese marco legal y discursivo asentado en los derechos y la seguridad humana la que funciona como pre-texto para la definición del contorno de validez de la ley, y, con ello, de los campos en los que se manifiesta la excepción y el control. Planteamos con esta idea en realidad dos conjeturas: primero, que desde la perspectiva geográfica señalada arriba, el territorio mexicano puede ser significado como zona de intemperie en su situación como "afuera" respecto del norte global y, enseguida, que dentro de las propias normas vigentes en México se constituyen huecos de excepcionalidad que funcionan como espacios de privilegio para la autoridad; ahí se expresan, jurídicamente hablando, los rasgos de inconstitucionalidad que hacen paradójicamente legales las violaciones a los derechos humanos. La primera de estas cuestiones se trata más adelante; de la segunda nos ocupamos en este apartado.

\footnotetext{
${ }^{8}$ Los cambios más recientes debidos a la influencia de los gobiernos de López Obrador y Trump, e incluso el recién iniciado periodo Biden, así como los fenómenos de resistencia que han motivado, como es el caso de las llamadas "caravanas migrantes", quedan fuera del análisis en este texto porque forman parte de la última fase de la investigación que estamos realizando y que se refiere precisamente a esas nuevas formas de resistencia. Cabe señalar que el presente artículo es un subproducto de la investigación "Migrar, sobrevivir, resistir" que realizan la y el autor en el seno de la Maestría Interinstitucional en Derechos Humanos de la Universidad Autónoma de Tlaxcala, México.

${ }^{9}$ Para Casillas, la ubicación de las estaciones migratorias "[...] situadas principalemente en las ciudades que concetan vías torales de transporte y en puntos estratégicos de internación marítima y aérea del sur y centro del país, así como en importantes ciudades del norte o pasos fronterizos hacia los Estados Unidos [...] constituye una especie de frontera migratoria vertical a lo largo del país, con sus ramificaciones a las vías de comunicación cercanas a las costas nacionales" (2002: 163). Varela (2019) argumenta que esa situación cambió y que México dejó de ser una frontera vertical para convertirse en un país "tapón", una barrera de contención que ha dado origen a nuevas formas de organización, como las caravanas migrantes, que implican un novedoso mecanismo de resistencia frente al endurecimiento de las políticas migratorias en México y en los Estados Unidos. Sin embargo, como se ha aclarado en la nota 8, el análisis de ese fenómeno excede por ahora a nuestro objetivo en este texto.
}

EntreDiversidades. Revista de Ciencias Sociales y Humanidades, Vol. 8, Núm. 2 (17), julio-diciembre 2021. Páginas: 167-190 ISSN-e: 2007-7610. https://doi.org/10.31644/ED.V8.N2.2021.A08 


\section{Pre-texto: la protección de los derechos humanos de las personas migrantes}

De acuerdo con el primer párrafo del artículo primero de la Constitución Política de los Estados Unidos Mexicanos, en su territorio nacional "todas las personas gozarán de los derechos humanos reconocidos en [la propia] Constitución y en los tratados internacionales de los que [el país] sea parte, así como de las garantías para su protección, [estos derechos no pueden] restringirse ni suspenderse salvo en los casos y bajo las condiciones que [la misma] Constitución establece”. El segundo párrafo ordena que todas las normas relativas a los derechos humanos se interpreten pro persona; el tercero, obliga a las autoridades mexicanas a respetar, promover, proteger y garantizar esos derechos y el quinto párrafo del mismo artículo prohibe la discriminación. ${ }^{10}$

Que la condición migratoria no debe ser obstáculo para el acceso a esos derechos y a sus garantías se desprende, a nuestro entender, justamente de una interpretación pro persona de los párrafos primero, tercero y quinto del artículo primero constitucional e incluso de las propias restricciones que a los derechos políticos — como el derecho de petición o el derecho a votar y ser votado o a desempeñar cargos reservados para mexicanos - imponen normas constitucionales anteriores a la reforma de junio de 2011 y que, desde la doctrina y el activismo político y social, se han venido cuestionando con éxito. Incluso, la facultad de expulsión que se arroga el Estado mexicano en el artículo 33 constitucional está limitada por el derecho al debido proceso exigido en el párrafo segundo de ese mismo artículo.

Tal vez podría discutirse que la condición de migrante documentado supone un estatus de naturaleza administrativa que está sujeto a requisitos procedimentales relacionados con la necesidad de mantener controles que den certeza a la información que sobre el ingreso, permanencia y salida de personas en su propio territorio requiere un país, y que a él tienen derecho todas las personas de cualquier origen étnico o nacionalidad siempre que cumplan con los requisitos para obtenerlo por lo que, en principio, tales controles no son discriminatorios. Sin embargo, aun si existió una violación a las normas administrativas de ingreso documentado al país, ello solo puede suponer que la persona en cuestión no posee la categoría de migrante con documentos pero, de ninguna manera, que pierda su condición de persona y, en consecuencia, tampoco sus derechos humanos. Por esta razón, si la persona ya está en territorio nacional, con independencia de cómo ingresó, el primer párrafo del artículo primero y todo el marco constitucional de derechos, incluidos los que se contienen en los tratados internacionales a los que se refiere ese mismo artículo, le otorga derechos humanos con sus respectivas garantías. Luego, el párrafo quinto ya mencionado prohíbe la discriminación por origen étnico o nacional, lo que supone que esos derechos son exactamente los mismos que tendría cualquier otra persona que habite o transite por el territorio nacional, sea o no sea mexicano; y finalmente, de acuerdo con el párrafo tercero, en relación con los párrafos primero y quinto del mismo artículo primero constitucional, las autoridades mexicanas están obligadas a respetar, proteger, promover y garantizar los derechos de las personas migrantes

\footnotetext{
${ }^{10}$ De acuerdo con el texto del artículo primero constitucional reformado el 10 de junio de 2011 y vigente hasta la fecha (ver Constitución Política de los Estados Unidos Mexicanos, 2021). Para un análisis detallado de las normas que en los tratados internacionales obligan al Estado mexicano al respeto, promoción y garantía de los derechos humanos de las personas migrantes véase Guevara (2014).
}

EntreDiversidades. Revista de Ciencias Sociales y Humanidades, Vol. 8, Núm. 2 (17), julio-diciembre 2021. Páginas: 167-190 ISSN-e: 2007-7610. https://doi.org/10.31644/ED.V8.N2.2021.A08 
no documentadas que se encuentren en suelo mexicano, al menos mientras se documenta debidamente su estancia. De ahí la importancia de distinguir entre estar sin documentos y ser indocumentado.

Del análisis realizado se sigue que, en México, la Constitución protege los derechos de las personas migrantes no documentadas y, de hecho, haciendo una interpretación contrario sensu de las razones por las que se se prefirió utilizar "todas las personas" en lugar de "las y los ciudadanos", "las y los mexicanos" o "todos quienes posean residencia legal" o cualquier otro fraseo que resultase limitativo, se podría afirmar que el constituyente da por hecho que habrá en territorio nacional personas migrantes indocumentadas y que por ello es necesario que, mientras estén pisando suelo mexicano y hasta que su situación migratoria se resuelva, sus derechos humanos deben ser respetados, protegidos y garantizados. Ello se refuerza porque en la misma reforma constitucional de junio de 2011 se modificó el texto de los párrafos primero y segundo del artículo 33 constitucional para garantizar derechos humanos a los extranjeros y para establecer el derecho de audiencia y a un procedimiento administrativo previo a que el Estado ejerza su facultad de expulsión.

Si entonces es claro que desde la perspectiva jurídico constitucional la migración indocumentada no representa sino un problema administrativo, la realidad del fenómeno migratorio y las políticas desde las que se lo ha enfrentado tendrían que considerarse sobredimensionadas. ${ }^{11}$ Pero la distancia entre la protección constitucional de las personas migrantes no documentadas y la cotidiana violación de sus derechos responde, como hemos planteado más arriba, a otro registro. Por ello, el desarrollo en legislación secundaria que debió establecer un conjunto de garantías para la que la política migratoria del país hubiese sido armónica en relación con el artículo primero constitucional resultó al final muy otro. La ausencia de garantías para los derechos de las personas migrantes indocumentadas hace completamente inocuo el potencial de esos derechos y torna el discurso acerca de su protección en una eficiente retórica que encubre, como mostramos enseguida, el propósito que se haya detrás de ella.

\section{Texto: el muro legal contra la inmigración no documentada}

Es importante considerar que el tema migratorio no poseía en México una entidad jurídica propia. Hasta mayo de 2011, la Ley General de Población se encargaba de regular la migración, vigente desde 1974, pero cuyos contenidos en materia migratoria datan en realidad de las anteriores leyes de población de 1936 y de 1947 (Perales, 2013). Aunque era de esperarse que siendo la migración un asunto sensible en relación con los derechos humanos la legislación secundaria en la materia se hubiese desarrollado a partir de similares motivos a los que se adujeron para la gran reforma constitucional que precisamente en materia de derechos humanos se aprobó el 10 de junio de ese mismo 2011 —es decir, unos 15 días después de que se emitiera la primera ley de migración en el país, que data del 25 de mayo-, sus antecedentes y sus resultados obedecen a otras razones.

\footnotetext{
${ }^{11}$ Sobre todo si se toman en cuenta la totalidad de las leyes de "protección” y de "inclusión" que Bobes y Pardo (citados por Canales y Rojas, 2017) señalan como parte del marco de derechos humanos que, hoy, por efecto del artículo primero constitucional darían forma al parámetro de control de la regularidad constitucional en la materia.
}

EntreDiversidades. Revista de Ciencias Sociales y Humanidades, Vol. 8, Núm. 2 (17), julio-diciembre 2021. Páginas: 167-190 ISSN-e: 2007-7610. https://doi.org/10.31644/ED.V8.N2.2021.A08 
Hay que decir, sin embargo, que la Ley de Migración fue considerada un importante logro, seguramente porque fue el producto final de un esfuerzo de años entre las organizaciones de la sociedad civil, la academia y las distintas fuerzas políticas que contribuyeron a su propuesta y discusión al menos desde el 2005 (Perales, 2013), y en parte también porque se enmarca en una serie de principios que están destinados al respeto irrestricto de los derechos humanos de las personas migrantes (Correa, 2014; López, 2017). Pero quizá lo más importante es que determina, con toda claridad, que estar en México sin documentos no constituye, de ningún modo, un delito (ver LM, art. 2, párr. 2).

De acuerdo con la exposición de motivos publicada en el decreto de la iniciativa que precedió a la versión que finalmente se publicó de la Ley de Migración —y que fue presentada por legisladores de los grupos parlamentarios de los tres principales partidos políticos mexicanos en diciembre de 2010 - ${ }^{12}$ era menester reconocer que el país estaba ya inmerso en un mundo globalizado en el que la movilidad humana iba en incremento, no solo para perseguir fines lícitos, sino tambien ilícitos. Por esa razón, en resumen, parafraseando a la exposición de motivos de la ley, se puede decir que la política migratoria fue concebida desde entonces como un medio para: 1) facilitar la movilidad hacia y desde México de las personas migrantes documentadas; 2) darles protección, asistencia y facilitar su integración a las sociedades receptoras; 3) ello al amparo de los principios de tolerancia y no discriminación; 4) en el marco del Estado de Derecho, la democracia, los derechos humanos; y 5) con el compromiso de velar por la seguridad humana de los migrantes nacionales y extranjeros. Al mismo tiempo, a la política migratoria le correspondería también cuidar el mercado laboral nacional de los posibles efectos de migraciones masivas y fomentar la seguridad nacional y la seguridad pública, combatiendo las redes de tráfico y explotación de migrantes, y previniendo y controlando "[...] con determinación la migración indocumentada, salvaguardando la integridad y los derechos humanos de los migrantes” (Iniciativa [...] de Ley de Migración [...], 2010: 2).

Como ocurre con la redacción de esta exposición de motivos, la lectura de los contenidos de la Ley de Migración muestra igualmente una tensión entre el propósito explícito de fomentar la migración documentada - e insistir en el respeto a los derechos de las personas migrantes documentadas - y el propósito subyacente de endurecer la política migratoria cuando se refiere a la migración no documentada. Como en la célebre cita de Anatole France, la Ley de Migración pensada para migrantes documentados e indocumentados solo es relativamente útil para los primeros, que en los términos del marco constitucional de derechos humanos vigente en México no la necesitan, y absolutamente útil para cumplir con el propósito subyacente de administrar la entrada y el tránsito de quienes migran sin documentos. ${ }^{13}$

${ }^{12}$ Disponible en http://sil.gobernacion.gob.mx/Archivos/Documentos/2010/12/asun 27213892010120912919
$11767 . p d f$
${ }^{13}$ Este carácter permisivo y a la vez represivo de la Ley de Migración recuerda aquella célebre cita atribuida a Anatole
France que advierte a ricos y pobres de la prohibición de dormir bajo los puentes de París: "La Ley, en su magnífica
ecuanimidad, prohíbe, tanto al rico como al pobre, dormir bajo los puentes, mendigar por las calles y robar pan"
(traducción popular derivada de un famoso pasaje del libro Le Lys Rouge de Anatole France publicado en 1894:
"Nous sommes militaires, en France, et nous sommes citoyens. Autre motif d'orgueil, que d'être citoyen! Cela
consiste pour les pauvres à soutenir et à conserver les riches dans leur puissance et leur oisiveté. Ils y doivent travailler

EntreDiversidades. Revista de Ciencias Sociales y Humanidades, Vol. 8, Núm. 2 (17), julio-diciembre 2021. Páginas: 167-190 ISSN-e: 2007-7610. https://doi.org/10.31644/ED.V8.N2.2021.A08 
Esta posición se verifica sin duda en su articulado, donde las previsiones acerca de la migración no documentada son notoriamente represivas. Por ejemplo, la Ley erige una institucionalidad de carácter defensivo, un muro legal, por así decirlo, que eleva el estatus del Instituto Nacional de Migración (INM) — considerado como una instancia de seguridad nacional desde el año 2005 (Calleros, 2010) — a rango de autoridad encargada de llevar a cabo el aseguramiento de las fronteras y de las personas migrantes indocumentadas, así como de coordinar los procedimientos destinados a prevenir el ingreso de personas sin documentos, pero también la detección, detención, encierro y deportación de quienes lograron ingresar y ya transitan por el país. Además, se aprecia en la legalización la existencia de cuerpos especiales de agentes cuyo objetivo formal es el de "auxiliar a las personas migrantes no documentadas" 14 — conocidos desde los noventa como grupos Beta, y referidos en la Ley como grupos de protección de migrantes- y también de los centros que en los primeros años del siglo se construyeron para el "alojamiento" de las personas migrantes indocumentadas que resultan "aseguradas" — eufemismo que la ley usa en lugar de detenidas - . La ley otorga al INM facultades para coordinar a los grupos de protección de migrantes, así como para las acciones de verificación y revisión migratoria, la "presentación de extranjeros" y la gestión de las estaciones migratorias — que así es como denomina la ley a los centros de detención-. Cabe señalar que estas acciones no se realizan solo en los puntos de entrada o salida del país, sino que las autoridades migratorias se encuentran distribuidas en todo el territorio nacional para, al amparo de la ley, solicitar documentos a las personas que se hallan en tránsito y, en su caso, "asegurarlas", "presentarlas" y "alojarlas" en las estaciones migratorias. ${ }^{15}$

Mas allá de los eufemismos, resulta evidente que la Ley de Migración crea un sistema de justicia paralelo en el que, bajo su cobertura legal y en función de la dimensión autoritativa que adquiere el INM, las y los agentes migratorios detectan, detienen y encierran contra su voluntad a las personas migrantes sin documentos que transitan por territorio mexicano en centros de reclusión forzada, mediante procesos administrativos cuasi jurisdicionales en los que

devant la majestueuse égalité des lois, qui interdit au riche comme au pauvre de coucher sous les ponts, de mendier dans les rues et de voler du pain”. Ver http://alsosprachblog.blogspot.com/2019/01/335.html).

${ }^{14}$ Ello de acuerdo con el artículo 71 de la Ley de Migración. Vale recordar que los grupos Beta emergieron de un programa piloto que en los noventa se creó en Tijuana para auxiliar a las personas migrantes víctimas de la delincuencia. Según lo consigna la página web del Instituto Nacional de Migración, a la fecha hay 22 grupos Beta distribuidos en 9 estados de la República: Baja California, Sonora, Chihuahua, Coahuila, Tamaulipas, Veracruz, Tabasco, Chiapas y Oaxaca (https://www.gob.mx/inm/acciones-y-programas/grupos-beta-de-proteccion-a-migrantes).

15 "Presentar" es otro eufemismo utilizado por la ley para evitar decir que en realidad se les pone a disposición de la autoridad. Una "puesta a disposición" implica la pérdida de la libertad, que al no ser el resultado de una orden de aprehensión emitida por un fiscal y autorizada por un juez, se torna ilegal. Lo mismo ocurre con "alojar", que virtualmente es privarles de la libertad en una "estación migratoria" que en los hechos funciona como un centro de detención. Como se puede apreciar, se trata de un sistema que utiliza eufemismos para invisibilizar su naturaleza para-penal.

EntreDiversidades. Revista de Ciencias Sociales y Humanidades, Vol. 8, Núm. 2 (17), julio-diciembre 2021. Páginas: 167-190 ISSN-e: 2007-7610. https://doi.org/10.31644/ED.V8.N2.2021.A08 
las autoridades migratorias actúan como juez y parte. ${ }^{16}$ En consecuencia, se puede decir, sin duda, que la ley ordena a las autoridades migratorias a cometer violaciones a los derechos humanos de las personas migrantes no documentadas, pues, al no ser esta una conductua delictiva, los aseguramientos constituyen detenciones arbitrarias, los encierros forzados se vuelven formas de privación ilegal de la ibertad y la ausencia de control judicial sobre el procedimiento viola las garantías orgánicas de independencia, imparcialidad y separación entre juez y acusador que son fundamentales para el debido proceso. ${ }^{17}$

En realidad, la Ley de Migración vino a dar cobertura legal a un conjunto de dispostivos que han sido instaurados como mecanismos de control destinados a la gestión migratoria como efecto de la cooperación con el gobierno estadounidense, especialmente despues del $11 \mathrm{~s}$ - que si bien no es el origen del proceso de securitización, funcionó como un importante catalizador- Entre ellos, Calleros (2010) incluye la formación de grupos de alto nivel para la seguridad fronteriza entre México, Belice y Guatemala, fundados en sendos memoranda y entre cuyos temas de interés estaban: migración y derechos humanos, asuntos fronterizos, terrorismo y seguridad internacional, crimen organizado y cooperación jurídica, seguridad pública y aduanas (GANSEF, constituido por México y Guatemala en mayo de 2002); migración, seguridad y terrorismo internacional, seguridad pública y aduanas (GANSEF, constituido por México y Belice en junio de 2005) y nuevamente migración y derechos humanos, asuntos fronterizos, terrorismo y seguridad internacional, delincuencia organizada y cooperación jurídica, seguridad pública y aduanas (GANSEG, en una revisión del GANSEF, constituido por México y Guatemala en junio de 2008). ${ }^{18}$ Asimismo,

\footnotetext{
${ }^{16} \mathrm{Al}$ respecto, puede verse el informe "Detención migratoria y tortura: del estado de excepción al estado de derecho", del Grupo Impulsor contra la Detención Migratoria y la Tortura (2018). También puede consultarse el resumen ejecutivo del estudio del Consejo Ciudadano del Instituto Nacional de Migración (2017) titulado "Personas en detención migratoria en México. Misión de monitoreo de estaciones migratorias y estancias provisionales del Instituto Nacional de Migración”. Finalmente, es igualmente recomendable el informe regional de la International Detention Coalition, "¿Qué esperamos del futuro?. Detención migratoria y alternativas a la detención en las Américas" (Coria, Bonnici y Martínez, 2017).

${ }^{17}$ Por razones de espacio no exploramos aquí el Reglamento de la ley que, al aterrizar disposiciones de la misma, operacionalizan en prácticas concretas la política migratoria nacional; sin embargo, como resulta esperable, puede considerársele una suerte de contrafuerte para el refuerzo del muro legal que supone la Ley de Migración (ver Perales, 2013).

${ }^{18}$ De acuerdo con Rioja (2015: 43): “El eslabón de la cooperación regional en materia de seguridad fronteriza en el Sur de México se plasma en el Grupo de Alto Nivel de Seguridad Fronteriza (GANSEF), acordado por parte de México y Guatemala en el 2002, y por parte de México y Belice a partir del 2005. Cabe destacar que, si bien los tres países están vinculados en torno al GANSEF, las relaciones caen en el ámbito bilateral de sus relaciones con México, por lo que su marco de acción es limitado. Este grupo está constituido por representantes de las instituciones nacionales de cada país, encargadas de los asuntos de seguridad nacional, seguridad pública, delincuencia organizada, migración y procuración de justicia. En este sentido, las reuniones y las mesas de trabajo se organizan con la contraparte de los otros países. En el caso de México, se trata de un organismo que no es atendido por las altas esferas del gobierno, sino que involucra a diversos funcionarios que fungen como enlace técnico y como operativos frente a sus contrapartes centroamericanos, pertenecientes a las Secretarías de Relaciones Exteriores; a Gobernación, por medio del Centro de Investigación y Seguridad Nacional; a la Procuraduría General de la República; al Instituto Nacional de Migración y a la Secretaría de Comunicaciones y Transportes".
}

EntreDiversidades. Revista de Ciencias Sociales y Humanidades, Vol. 8, Núm. 2 (17), julio-diciembre 2021. Páginas: 167-190 ISSN-e: 2007-7610. https://doi.org/10.31644/ED.V8.N2.2021.A08 
[...] la modernización y automatización de la operación migratoria en materia de verificación de la documentación de extranjeros en puntos de internación terrestres, marítimos y aéreos [...] [lo que permite] realizar la detección oportuna, de acuerdo con las alertas emitidas, de extranjeros que se internan en México, buscados por agencias internacionales o por sus países de residencia $\mathrm{u}$ origen por ser presuntos responsables de la comisión de diversos delitos, especialmente contrabando, narcotráfico, tráfico de drogas, armas o personas entre otros (Calleros, 2010: 35).

Calleros (2010: 35) añade, entre las acciones emprendidas por el Estado mexicano, las siguientes:

- Intercambio de información con los servicios de inteligencia nacionales.

- Actualización y digitalización del Registro Nacional de Extranjeros.

- Operativos y acciones coordinadas con otras instituciones involucradas en la seguridad nacional (CISEN [Centro de Investigación y Seguridad Nacional], PGR [Procuraduría General de la República], SRE [Secretaría de Relaciones Exteriores], SSA [Secretaría de Salubridad y Asistencia, hoy Secretaría de Salud], entre otras).

- Fortalecimiento de la modernización y eficiencia del Sistema Integral de Operación Migratoria (SIOM).

- Optimización del registro de entradas de extranjeros.

- Automatización del sistema de alarmas migratorias para la detección de extranjeros que poseen antecedentes penales y presuntos terroristas.

- Mejor detección de documentos de viaje falsificados, robados o extraviados.

- Capacitación periódica a agentes migratorios.

Así, se muestra que este carácter aparentemente contradictorio entre un discurso de protección de derechos y una serie de permisiones legales para violentarlos es complementario de la gestión burocrática que, al lado de la ley, opera mediante tecnologías de seguridad que permiten ejercer gobierno sobre la migración. Desde esta perspectiva fisiológica, el recurso a los derechos inocula la espectacularización en torno a la amenaza. "En consecuencia - dice Campesi- el proceso de securitización no se produce mediante discursos o retóricas que invocan la necesidad de superar el marco jurídico político ordinario para responder a una inesperada amenza existencial, sino que se desarrolla en la práxis concreta de los burócratas dedicados a la gestión cotidiana de la inseguridad" (Campesi, 2012: 10).

\section{El sur global como zona de excepción: el caso mexicano}

A nuestro modo de ver, es un error de perspectiva referir el proceso de securitización a los atentados del 11s y también lo es intentar situarlo en la decisión soberana de un país en particular. Si la securitización es concomitante a la redefinición geopolítica del mundo en términos de un norte y un sur global, ese proceso debe entenderse como el producto de la nueva gobernanza mundial

EntreDiversidades. Revista de Ciencias Sociales y Humanidades, Vol. 8, Núm. 2 (17), julio-diciembre 2021. Páginas: 167-190 ISSN-e: 2007-7610. https://doi.org/10.31644/ED.V8.N2.2021.A08 
que empezó a construirse desde finales de los años ochenta en todo occidente como efecto de la racionalidad neoliberal. En esa lógica, el sur se afirma como la fuente de las commodities que el norte necesita para su bienestar: desde luego, materias primas, pero también fuerza de trabajo. Todo ello funciona bajo una compleja lógica extractivista que implica procesos transnacionales desiguales en desmedro del sur (Gudynas, 2018). En el caso de la extracción de la fuerza de trabajo, además, conlleva el "inconveniente" de que se hace a partir de seres humanos.

Por eso, el fenómeno migratorio es complejo; porque delas personas migrantes indocumentadas se requiere mano de obra, para nada su integridad y, en consecuencia, tampoco su ciudadanía. Siguiendo a Agamben (1998), la securitización "desnuda" al migrante, hace "nuda" su vida y la vuelve sacrificable. La excepción como atribución única del Soberano, sitúa esa "vida nuda" por fuera del contorno de la ley e inscribe en su ser la condición de desechable; sin embargo —afirmamos_-, mientras mantenga su fuerza de trabajo conservará también una condición de commodity, de la que solo podrá desprenderse cuando ya no haya más que extraerle. Para quien logra emplearse, su fuerza de trabajo le mantendrá dentro, aunque en el fondo sea siempre un eterno habitante del afuera. ${ }^{19}$ Pero para quien no lo logra o para quien habiéndolo logrado es expulsado, la historia es muy otra.

Es el soberano quien decide y, como solía decir hace unos treinta ańos el filósofo italiano Eligio Resta (1992), cuando decide ucide. En efecto, si la violencia de la ley se expresa en el resultado de una decisión es porque cuando se decide se elige y cuando se elige se descarta. Desde esta perspectiva, la securitización es también una acción de descarte, mediante la cual la Soberanía decreta a quién se incluye y a quién se excluye; porque el decreto de exclusión, la puesta "a-bando", es a su vez una condena, un destierro.

Esto explicaría por qué el fenómeno securitizante es al mismo tiempo incluyente y excluyente: posee una fisiología que al final opera necesariamente sobre el espacio entre la norma y la excepción. La fisiología de la securitización asume que el migrante indocumentado es una consecuencia del propio proceso de globalización y, por tanto, le considera suceptible de gobierno y de administración. La geografía de la securitización distingue claramente entre un adentro reservado donde rigen la ley y los derechos para la cuidadanía y un afuera como intemperie, como abandono, y por tanto como excepción, al que deben ser condenados impunemente los homini sacri. ${ }^{20}$ En la interacción de ambas miradas se entiende el sentido que, según Varela (2019), tiene para los migrantes centroamericanos el territorio mexicano como frontera vertical porque,

\footnotetext{
${ }^{19}$ Esta es la dialéctica de la inclusión/excluyente, según hemos propuesto en otros trabajos (González y Díaz de León, 2020).

${ }^{20}$ Para Campesi (2012: 10) estos dos ángulos representan las dos principales tradiciones desde las que teóricamente se ha pensado la securitización: de una parte, la atribuible a los trabajos de Foucault (2002), remisibles al curso que bajo el título Defender la Sociedad impartió en el Collège de France en 1976 y para la cual la securitización se expresa como una gubernamentalidad asociada al control técnico en manos de burócratas y expertos, y, por la otra, la influencia de los trabajos de Agamben, especialmente en torno al Estado de Excepción (1998 y 2003). Coincidimos, desde luego, con el criminólogo italiano en que estos representan dos enfoques que suponen miradas bien distintas sobre la persona migrante — una claramente como mercancía y la otra más bien como enemigo— así como de la función biopolítica de los confines - el confín como espacio poroso e impermeable frente al confín como desmarque de un espacio de anomia y de violencia; pero igualmente pensamos que considerarlas como lógicas complementarias contribuye a entender la dinámica del fenómeno migratorio en su dimensión actual.
}

EntreDiversidades. Revista de Ciencias Sociales y Humanidades, Vol. 8, Núm. 2 (17), julio-diciembre 2021. Páginas: 167-190 ISSN-e: 2007-7610. https://doi.org/10.31644/ED.V8.N2.2021.A08 
en efecto, por un lado, la idea de la frontera como espacio de administración de la migración no documentada echa mano, como hemos visto, no solo de la ley, sino de la incorporación de tecnologías, de estrategias y, de hecho, enlazada como lo está con la retórica misma del objetivo biopolítico de prevenir permite el adelantamiento de las barreras de protección, lo que en este caso implica la deslocalización de las líneas fronterizas, es decir, su externalización. Esta misma circunstancia permite entender también el fenómeno de inmovilidad forzada que ha sido descrito por Carmen Fernández y Arli Juárez (2019) y que está en la base del incremento de la relación entre migración y violencia, del alza en las solicitudes de asilo y del cambio de rutas para cruzar por el país. Y es que los dispositivos de seguridad permiten avanzar los controles migratorios a la frontera sur de México y comenzar el proceso de gobierno y administración de la migración no documentada, desde cualquiera de los puntos en los que los migrantes centroamericanos intentan ingresar y permanecer en territorio mexicano. ${ }^{21}$

Por el otro lado, la idea del límite fronterizo como demarcación del espacio de legalidad respecto del que no lo es define los contornos fuera de los cuales la anomia y la violencia se ejercen como normalización de la excepcionalidad. En este sentido, podría decirse que la excepción porta su propio confín y que, en este caso, representa la línea sobre la que se decide que la muerte de unos —en el sur global — es un sacrificio necesario para la seguridad de otros —en el norte global—.

Cabe reconocer que, para el caso mexicano, esta es mucho más que solo una metáfora: cientos de miles de muertos, decenas de miles de desaparecidos, personas privadas legal e ilegalmente de la libertad, incontables personas victimizadas por los grupos criminales. ${ }^{22}$ En lo que va del siglo XXI, México se ha convertido en un territorio atravesado por la violencia y por la muerte (Casillas, 2012). Las razones por las que esto ha sido así son múltiples y desarrollarlas aquí excede el propósito de este texto. Sin embargo, es necesario decir que tales motivos han obedecido al cruce de distintos procesos que confluyen, en síntesis, en la emergencia de

[...] "territorios de muerte" [...] territorios de excepción, zonas fragmentarias que por sus recursos o su ubicación estratégica quedaron fuera de toda protección del derecho y expuestas a soberanías locales, narcopolíticas, que desplegaron violencias desmedidas, asesinatos, feminicidios, desplazamiento forzado y [...] desaparición de personas (Calveiro, 2021: 43-44).

Como telón de fondo, están los efectos que la racionalidad neoliberal tuvo también en las relaciones entre el Estado y los mercados criminales — mediada través de la corrupción-. En la relación con los mercados legales, frente a los ilegales el Estado se comporta igualmente como un gerente que ejerce un gobierno corporativo destinado no solamente a no interferir, sino a

\footnotetext{
${ }^{21}$ Ello daría más la idea de un prisma que presenta una cara no tratada en este artículo — porque, como se ha insistido, constituye el objeto de una reflexión de publicación futura- que es la de la resistencia (ver supra nota 8). En este sentido, Rivas (2008 y 2011) y más recientemente Porraz (2015 y 2019) y Varela (2017 y 2019) han estudiado algunas de estas formas de resistencia que van desde la creación de redes de apoyo hasta las carvanas de migrantes, en contextos que son vividos, tanto en México como en los Estados Unidos, como experiencias cien por ciento expulsoras.

${ }^{22}$ Ver, por ejemplo, Casillas (2010). Seguramente es el caso también de otros países centroamericanos, por ejemplo, El Salvador (ver Kinosian, Albaladejo y Haugaard, 2016).
}

EntreDiversidades. Revista de Ciencias Sociales y Humanidades, Vol. 8, Núm. 2 (17), julio-diciembre 2021. Páginas: 167-190 ISSN-e: 2007-7610. https://doi.org/10.31644/ED.V8.N2.2021.A08 
proteger sus intereses. Así, explica Calveiro (2021), la connivencia entre cárteles y autoridades configura en esos territorios de excepción traslapes en los que el gobierno de las autoridades se confunde con el de los grupos criminales, difuminando también los límites entre la violencia estatal — legal e ilegal_ y la violencia privada.

En este contexto de multilateralidad de la violencia, los enfrentamientos entre las fuerzas armadas y los cárteles criminales, así como los que han tenido lugar entre cárteles rivales o incluso entre las propias corporaciones del orden - agentes municipales contra agentes estatales o federales, por ejemplo- hicieron de gran parte del suelo nacional territorio de disputa necesitado asimismo de mano de obra y de otras "servidumbres", incluidas, desde luego, las de naturaleza sexual. Esta circunstancia creó nuevos mercados para la mano de obra gratuita que podía obtenerse de la migración indocumentada: personas sin registro oficial, invisibles durante su estancia en territorio nacional, necesitadas de recursos para completar su trayecto, vinculadas con sus familias en sus sitios de origen donde esperaban noticias suyas y, finalmente, con la esperanza de cruzar la frontera norte de México para estar en condiciones de ganar dinero y convertirlo en remesas para enviarlas a sus hogares en Centroamérica. ${ }^{23}$

En esas circunstancias, estas personas pueden ser obligadas a todo, porque estan a merced de la voluntad soberana que gobierna el espacio de la excepción. En su condición de "vidas que no merecen ser vividas", son también vidas que pueden ser impunemente masacradas, como lo evidenció el hallazgo de 72 migrantes centroamericanos asesinados por un cártel criminal en San Fernando, Tamaulipas, en agosto de 2010 (Aguayo, et al., 2016), evento al que han seguido múltiples matanzas de migrantes — la más reciente este mismo año, el 22 de enero, en ciudad Camargo, también en Tamaulipas (Aristegui Noticias, 2021)—.

La frontera vertical no es solamente, por tanto, el espacio donde opera el control burocrático de la migración; es también el foso que precede a la fortificación.

\section{Reflexiones conclusivas}

El análisis realizado a través de este texto nos permite concluir que la securitización como concepto posee un significado amplio que sirve al mismo tiempo a los fines de la selección y de la exclusión como mecanismos complementarios en el aseguramiento de la integridad identitaria y cultural del norte global. Como práctica, supone el recurso a dispositivos normativos y de gestión que tienen como finalidad gobernar a distancia las amenazas que se relacionan con la movilidad humana, permitiendo el adelantamiento de las barreras de protección hacia el sur sobre territorios en los que esos dispositivos no solo son puestos en marcha, sino que además funcionan para delimitar las zonas de destierro (donde quienes no están bajo el amparo de la ley son puestos "a-bando") en las que lo que rige es la excepción.

En el caso mexicano, muy a pesar de lo que afirma el marco constitucional de derechos

\footnotetext{
${ }^{23}$ Para diversos autores, ha sido, precisamente, las modificaciones y el incremento en la intensidad de las medidas migratorias lo que ha obligado a los migrantes indocumentados a variar las rutas que siguen a lo largo del país hacia otras controladas por los cárteles de la delincuencia organizada y que los alejan de la protección que tradicionalmente han recibido de organizaciones eclesiales y de la sociedad civil (Farah, 2012; Varela, 2017; Vargas, 2018).
}

EntreDiversidades. Revista de Ciencias Sociales y Humanidades, Vol. 8, Núm. 2 (17), julio-diciembre 2021. Páginas: 167-190 ISSN-e: 2007-7610. https://doi.org/10.31644/ED.V8.N2.2021.A08 
humanos vigente a la fecha, el estigma de ilegalidad que la legislación secundaria imprime en la persona migrante en el momento mismo en el que ingresa sin documentos al teriritorio mexicano se convierte en la marca que, por una parte, le hace sujeto de persecución oficial mientras transita a lo largo de todo el país y, por la otra, también de cacería por parte de los grupos del crimen organizado que operan en las múltiples zonas en las que las leyes mexicanas no solamente no rigen, sino donde las autoridades permiten que se construyan zonas de excepción dejadas a la voluntad soberana de quienes las controlan.

Es así que se puede comprender que cuando una persona se convierte en migrante indocumentado — cuando, en sentido amplio queda proscrito por voluntad del Soberanose vuelve objetivo estratégico del proceso de securitización que, cada vez que sea necesario, le obstaculizará, le perseguirá, le contendrá y le desterrará mientras insista en su propósito de penetrar la barrera de seguridad del norte global.

\section{Bibliografía citada}

Agamben, Giorgio (1998). Homo Sacer. El poder soberano y la vida desnuda. 2a edición. Buenos Aires, Argentina: Adriana Hidalgo Editora.

Agamben, Giorgio (2003). Estado de excepción. Homo Sacer II, 1. Buenos Aires, Argentina: Adriana Hidalgo editora.

Aguayo Quezada, Sergio, et al. (2016). En el desamparo. Los zetas, el Estado, la sociedady las víctimas de San Fernando Tamaulipas (2010) y Allende, Coahuila (2011). Ciudad de México, México: El Colegio de México. También disponible en: https://eneldesamparo.colmex.mx/

Anitua, Gabriel Ignacio (2006). "La inmigración y los discursos de la inseguridad", en Bergalli, Roberto (coord.). Flujos migratorios y su (des)control. Puntos de vista pluridisciplinarios. Barcelona, España: Anthropos, pp. 135-158.

Aristegui Noticias (2021). "Detienen a 12 policías por masacre de migrantes en Camargo, Tamaulipas". Aristegui Noticias [en línea], 2 de febrero. Disponible en: https:// aristeguinoticias.com/0202/mexico/detienen-a-12-policias-por-masacre-de-migrantesen-camargo-tamaulipas/ (Consultado el 4 de julio de 2021).

Armijo Canto, Natalia (2011). "Introdución”, en Armijo Canto, Natalia (ed.). Migración y Seguridad: nuevo desafío en México. México, D.F., México: Colectivo de Análisis de la Seguridad con Democracia, pp. 5-10. Disponible en: https:/www.casede.org/index.php/ publicaciones/migracion-y-seguridad-nuevo-desafio-en-mexico (Consultado el 6 de febrero de 2021).

Benítez Manaut, Raúl (2011). "México, Centroamérica y Estados Unidos, migración y seguridad”, en Armijo Canto, Natalia (ed.). Migración y Seguridad: nuevo desafío en México. México, D.F., México: Colectivo de Análisis de la Seguridad con Democracia, pp. 179-192. Disponible en: https://www.casede.org/PublicacionesCasede/MigracionySeguridad/ cap10.pdf (6 de febrero de 2021).

Berger, Peter L. y Luckmann, Thomas (2003 [1966]). La construcción social de la realidad. Buenos

EntreDiversidades. Revista de Ciencias Sociales y Humanidades, Vol. 8, Núm. 2 (17), julio-diciembre 2021. Páginas: 167-190 ISSN-e: 2007-7610. https://doi.org/10.31644/ED.V8.N2.2021.A08 
Aires, Argentina: Amorrortu.

Brown, Wendy (2016). El pueblo sin atributos. La secreta revolución del neoliberalismo. Madrid, España: Malpaso.

Buzan, Barry, Ole Weaver y Jaap de Wild (1998). Security: A New Framework for Analysis. United States of America: Lynne Rinner Publishers.

Calleros Alarcón, Juan Carlos (2010). "El vínculo entre seguridad nacional y migración en México". Revista Mexicana de Política Exterior [en línea], Núm. 88, noviembre 2009febrero 2010, pp. 9-43. Disponible en: https://revistadigital.sre.gob.mx/images/stories/ numeros/n88/01calleros.pdff (Consultado el 28 de enero de 2021).

Calveiro, Pilar (2021). "Desaparición y gubernamentalidad en México". Historia y Grafía [en línea], Núm. 56, enero-junio, pp. 17-52. doi: https://doi.org/10.48102/hyg.vi56.355 (Consultado el 9 de febrero de 2021).

Campesi, Giusseppe (2012). "Migraciones, seguridad y confines en la teoría social contemporánea”. Revista Crítica Penal y Poder [en línea], Núm. 3, pp. 1-20. Disponible en: https://revistes. ub.edu/index.php/CriticaPenalPoder/article/view/3657/6724 (Consultado el 8 de febrero de 2021).

Canales Cerón, Alejandro y Rojas Weisner, Martha (2017). Panorama de la migración en México y Centroamérica. Documento elaborado en el marco de la Reunión Regional Latinoamericana y Caribeña de Expertas y Expertos en Migración Internacinal preparatoria del Pacto Mundial para una Migración Segura, Ordenada y Regular [en línea]. Santiago, Chile: Naciones Unidas, Comisión Económica para América Latina y el Caribe, Organización Internacional para las Migraciones. Disponible en: https://repositorio.cepal.org/bitstream/ handle/11362/43697/1/S1800554 es.pdf (Consultado el 16 de mayo de 2021).

Carbonell, Miguel (2014). Los derechos humanos en México. Hacia un nuevo modelo. México, D. F., México: Instituto Interamericano de Derechos Humanos, Editorial Ubijus, Centro de Estudios de Actualización en Derecho, Universidad Nacional Autónoma de México.

Casillas, Rodolfo (2002). "El Plan Sur de México y sus efectos sobre la migración internacional". Debate, Núm. 56, pp. 199-210.

Casillas, Rodolfo (2008). "Las rutas de los centroaméricanos por México, un ejercicio de caracterización, actores principales y complejidades". Migración y Desarrollo [en línea], Núm. 10, pp. 157-174. doi: https://doi.org/10.35533/myd.0610.rcr (Consultado el 16 de mayo de 2021).

Casillas, Rodolfo (2010). "Masacre de transmigrantes. Reflexiones e interrogantes sobre el significado del asesinato de 72 migrantes". Foreing Affairs Latinamérica [en línea], 10 (4), pp. 52-59. Disponible en: https://revistafal.com/numeros-anteriores/fal-10-4/ (Consultado el 16 de mayo de 2021).

Casillas, Rodolfo (2012). "La mundialización del delito, redes de tráfico y trata de personas en México". Nueva Sociedad, Núm. 241, septiembre-octubre, pp.122-132. También disponible en: https://nuso.org/articulo/la-mundializacion-del-delito-redes-detrafico-y-trata-de-personas-en-mexicol

Chomsky, Aviva (2014). Indocumentados. Cómo la inmigración se volvió ilegal. México, D.F.,

EntreDiversidades. Revista de Ciencias Sociales y Humanidades, Vol. 8, Núm. 2 (17), julio-diciembre 2021. Páginas: 167-190 ISSN-e: 2007-7610. https://doi.org/10.31644/ED.V8.N2.2021.A08 
México: Crítica.

Chomsky, Noam (2017). Réquiem por el sueño americano. Los diez principios de concentración de la riqueza y el poder. Ciudad de México, México: Sexto Piso.

Consejo Ciudadano del Instituto Nacional de Migración (CCINM) (2017). Personas en detención migratoria en México. Misión de monitoreo de estaciones migratorias y estancias provisionales del Instituto Nacional de Migración. Resumen Ejecutivo [en línea]. Ciudad de México, México: CCINM. Disponible en: https://tbinternet.ohchr.org/Treaties/CESCR/ Shared\%20Documents/MEX/INT CESCR CSS MEX 28755 S.pdf (Consultado el 7 de julio de 2021).

Constitución Política de los Estados Unidos Mexicanos (2021). Constitución Política de los Estados Unidos Mexicanos 1917 y reformas posteriores. Diario Oficial de la Federación, México. Disponible en: http://www.diputados.gob.mx/LeyesBiblio/pdf/1 280521.pdf (Consultado el 29 de enero de 2021).

Coria Márquez, Elba, Giselle Bonnici y Vanessa Martínez (2017). ¿Qué esperamos del futuro?. Detención migratoria y alternativas a la detención en las Américas [en línea]. Melbourne, Australia: International Detention Coalition. Disponible en: https://idcoalition.org/es/ publication/informe regional americas 2017/ (Consultado el 7 de julio de 2021).

Correa Cabrera, Guadalupe (2014). "Seguridad y migración en las fronteras de México: diagnóstico y recomendaciones de política y cooperación regional”. Migración y Desarrollo [en línea], 12 (22), pp. 147-171. doi: https://doi.org/10.35533/myd.1222.gcc (Consultado el 28 de enero de 2021).

Delgado, Manuel (2006). "Nuevas retóricas para la exclusión social”, en Bergalli, Roberto (coord.). Flujos migratorios y su (des)control. Puntos de vista pluridisciplinarios. Barcelona, España: Anthropos, pp. 1-24.

Durand, Jorge (2000). “Tres premisas para entender y explicar la migración México-Estados Unidos”. Relaciones [en línea], 21 (83), pp. 17-35. Disponible en: http://repositorio. cualtos.udg.mx:8080/jspui/handle/123456789/52 (Consultado el 16 de mayo de 2021).

Fanon, Frantz (1973 [1952]). Piel negra, máscaras blancas. Buenos Aires, Argentina: Editorial Abraxas.

Farah Cebara, Mauricio (2012). Cuando la vida está en otra parte. La migración indocumentada en México y en Estados Unidos. México, D.F., México: Editorial Porrúa.

Fernández Casanueva, Carmen Guadalupe (2012). “Tan lejos y tan cerca: Involucramientos transnacionales de inmigrantes hondureños en la ciudad fronteriza de Tapachula, Chiapas”. Migraciones Internacionales [en línea], 6 (23), pp. 139-172. doi: https://doi. org/10.17428/rmi.v6i23.729 (Consultado el 16 de mayo de 2021).

Fernández Casanueva, Carmen y Juárez Paulín, Arli (2019). "El punto más al sur y el punto más al norte: Tapachula y Tijuana como ciudades fronterizas escenarios de inmovilidades forzadas de migrantes, desplazados internos, solicitantes de refugio y deportados". Península [en línea], 14 (2), julio-diciembre, pp. 155-174. Disponible en: http://www.revistas.unam. mx/index.php/peninsula/article/view/70027 (Consultado el 16 de mayo de 2021).

García-Ramírez, Sergio y Morales Sánchez, Julieta (2011). La reforma constitucional sobre derechos

EntreDiversidades. Revista de Ciencias Sociales y Humanidades, Vol. 8, Núm. 2 (17), julio-diciembre 2021. Páginas: 167-190 ISSN-e: 2007-7610. https://doi.org/10.31644/ED.V8.N2.2021.A08 
humanos 2009-2011. México, D.F., México: Editorial Porrúa. También disponible en: https://www.te.gob.mx/formulario/media/files/40f7ff3778743f3.pdf

González Placencia, Luis (2001). "Intervención penal, enfermedad mental y desviación social: de la culpa sin responsabilidad a la responsabilidad sin culpa”. Alegatos, Núm. 47-48, enero-agosto, pp. 121-132. También disponible en: http://alegatos.azc.uam.mx/index. $\mathrm{php} / \mathrm{ra} /$ article/view/1580

González Placencia, Luis y Díaz de León Fernández de Castro, Laura (2020). "Movientes en resistencia. Migración, trabajo y abandono en el devenir de la economía-mundo capitalista”, en Hernández Sánchez, Mario y González Placencia, Luis (coords.). Los derechos humanos, de los márgenes al centro. Discusiones sobre ciudadanía, politica y derechos, Vol. 2. Ciudad de México, México: Universidad Autónoma de Tlaxcala, Ubijus Editorial, pp. 91-132.

González Placencia, Luis y Gluyas Millán, Ricardo (2006). "Criminalidad y derechos. Paradojas en el contexto de la interacción contemporánea entre Estado, individuo y mercado", en Rivera, Iñaki, et al. (coords.). Contornos y pliegues del derecho. Homenaje a Roberto Bergalli. Barcelona, España: Anthropos.

Grupo Impulsor contra la Detención Migratoria (2018). Detención migratoria y tortura: del estado de excepción al estado de derecho [en línea]. México: Instituto para la Seguridad y la Democracia. Disponible en: http://insyde.org.mx/pdf/informes/Detencion-migratoriay-tortura GIDMT.pdf (Consultado el 7 de julio de 2021).

Gudynas, Eduardo (2018). "Extractivismos: el concepto, sus expresiones y sus múltiples violencias". Papeles de relaciones ecosociales y cambio global [en línea], Núm. 143, pp. 61-70. Disponible en: https://www.fuhem.es/wp-content/uploads/2019/05/ Extractivismos-concepto-expresiones-violencias-E.GUDYNAS.pdf (Consultado el 2 de febrero de 2021).

Guevara Bermúdez, José Antonio (2014). "Conexiones entre los derechos humanos de las personas migrantes y la seguridad. ¿Es posible afirmar que el derecho mexicano criminaliza la migración indocumentada?”. Cuestiones Constitucionales. Revista Mexicana de Derechos Constitucional [en línea], Núm. 31, julio-diciembre, pp. 81-117. Disponible en: https:// revistas.juridicas.unam.mx/index.php/cuestiones-constitucionales/article/view/6068 (Consultado el 2 de febrero de 2021).

Harvey, David (2007). Breve historia del neoliberalismo. Madrid, España: Akal.

Hernández, José Carlos (2018). "La securitización del fenómeno migratorio en el caso del Programa Frontera Sur”. Global Strategy [en línea]. Disponible en: https://global-strategy. org/la-securitizacion-del-fenomeno-migratorio-en-el-caso-del-programa-frontera-

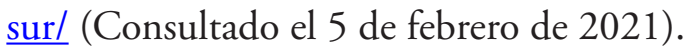

Iniciativa con proyecto de decreto por el que se expide la Ley de Migración y se reforman, derogan y

EntreDiversidades. Revista de Ciencias Sociales y Humanidades, Vol. 8, Núm. 2 (17), julio-diciembre 2021. Páginas: 167-190 ISSN-e: 2007-7610. https://doi.org/10.31644/ED.V8.N2.2021.A08 
adicionan diversas disposiciones de la Ley General de Población, de la Ley Aduanera, de la Ley Federal de Derechos, del Código Penal Federal, del Código Federal de Procedimientos Penales, de la Ley Federal contra la Delincuencia Organizada, de la Ley de la Policía Federal, de la Ley de Asociaciones Religiosas y Culto Público, de la Ley de Inversión Extranjera, de la Ley General de Turismo y de la Ley de Comercio Exterior (2010). México: Cámara de Diputados. Disponible en: http://sil.gobernacion.gob.mx/Archivos/Documentos/2010/12/asun 27 21389 20101209 1291911767.pdf (Consultado el 29 de enero de 2021).

Kinosian, Sarah, Angelika Albaladejo y Lisa Haugaard (2016). La violencia en el Salvador: no hay una solución sencilla [en línea]. El Salvador: Center for International Policy, Latin America Working Group Education Fund. Disponible en: https://securityassistance.org/ publications/la-violencia-en-el-salvador-no-hay-una-solucion-sencilla/ (Consultado el 28 de enero de 2021).

Ley de Migración (LM) (2011). Ley de Migración 2011. Diario Oficial de la Federación, México. Disponible en: https://www.dof.gob.mx/nota detalle. php? codigo $=5190774 \&$ fecha $=25 / 05 / 2011$ (Consultado el 29 de enero de 2021).

López Argoytia, Laura (2017). "Tránsitos y destinos de Sur a Norte. Conversación con Martha Rojas Wiesner”. Ecofronteras [en línea], 21 (60), pp. 34-37. Disponible en: https://revistas. ecosur.mx/ecofronteras/index.php/eco/article/download/1722/1674/ (Consultado el 29 de enero de 2021).

Mbembe, Achille (2011). Necropolitica. Tenerife, España: Melusina.

Melossi, Dario (1997). "State and Social Control à la Fin de Siècle. From the New World to the Constitution of the New Europe", en Bergalli, Roberto y Sumner, Colin (eds.). Social Control and Political Order. European Perspectives at the End of the Century. London, United Kingdom: Sage, pp. 52-74.

Monclús Masó, Marta (2005). "Hacia una política criminal diferenciada para los extranjeros: la consolidación de la expulsión como sanción penal especial”, en Rivera Veiras, Iñaki (coord.). Politica criminal y sistema penal. Viejas y nuevas realidades punitivas. Barcelona, España: Anthropos, pp. 330-347.

Moreno Rodríguez, Gleicys (2021). "La securitización del discurso migratorio. Nicaragua, un estudio de caso en América Latina”. Cuadernos Inter.c.a.mbio sobre Centroamérica y el Caribe [en línea], 18 (1), enero-junio. doi: https://doi.org/10.15517/C.A..V18I1.44751 (Consultado el 28 de enero de 2021).

Nancy, Jean-Luc (1983). "El ser abandonado", en Hernández B. Ernesto (trad.). Limpératif catégoric, pp. 139-153. Disponible en: https://es.scribd.com/document/127157793/El_ Ser-Abandonado-NANCY (Consultado el 29 de enero de 2021).

Orozco Restrepo, Gabriel Antonio (2006). "El aporte de la Escuela de Copenhague a los estudios de seguridad". Revista Fuerzas Armadas y Sociedad [en línea], Núm. 1, pp. 141-162. Disponible en: https://flacsoandes.edu.ec/sites/default/files/\%25f/agora/ files/escueladecopenhague.pdf (Consultado el 4 de febrero de 2021).

Pavarini, Massimo (1997). "Controlling Social Panic. Questions and Answers about Security

EntreDiversidades. Revista de Ciencias Sociales y Humanidades, Vol. 8, Núm. 2 (17), julio-diciembre 2021. Páginas: 167-190 ISSN-e: 2007-7610. https://doi.org/10.31644/ED.V8.N2.2021.A08 
in Italy at the End of the Millennium”, en Bergalli, Roberto y Sumner, Colin (eds.). Social Control and Political Order. European Perspectives at the End of the Century. London, United Kingdom: Sage, pp. 75-95.

Perales Garza, Claudia Yadira (2013). "Ley de Migración. 'Reforma a cuentagotas”. Boletín Mexicano de Derecho Comparado [en línea], Año 46, Núm. 137, mayo-agosto, pp. 749-767. doi: http://dx.doi.org/10.1016/S0041-8633(13)71148-7 (Consultado el 6 de febrero de 2021).

Porraz Gómez, Iván Francisco (2015). En los márgenes del sueño americano. Ser joven migrante retornado en el contexto de Chiapas, México. Serie Documentos de Trabajo, Red de Posgrados, Núm. 62. Buenos Aires, Argentina: Consejo Latinoamericano de Ciencias Sociales.

Porraz Gómez, Iván Francisco (2019). “'Salir a buscarse la vida! La experiencia de jóvenes”. Observatorio de las Democracias Sur de México y Centroamérica [en línea]. Disponible en: https://observatoriodelasdemocracias.com.mx/covid-19/f/;salir-a-buscarse-la-vida-laexperiencia-de-jóvenes (Consultado el 9 de mayo de 2021).

Rangel Aguirre, Adriana (2007). La securitización de las migraciones luego del 11 de septiembre. Construcción y control de un asunto de seguridad. Tesis para obtener el grado de Licenciatura en Ciencia Política. Universidad de los Andes, Departamento de Ciencia Política de la Facultad de Ciencias Sociales, Colombia. Disponible en: https://repositorio.uniandes. edu.co/handle/1992/25879 (Consultado el 8 de febrero de 2021).

Resta, Eligio (1992). La certezza e la speranza. Saggio su diritto e violenza. Roma-Bari, Italia: Laterza.

Rioja, Leonardo (2015). "El imaginario de la seguridad en la frontera sur de México a principios del siglo XXI". Revista Península [en línea], 10 (1), enero-junio, pp. 29-47. Disponible en: http://www.scielo.org.mx/scielo.php?script=sci arttext\&pid=S1870-57662015000100002 (Consultado el 8 de julio de 2021).

Ríos Vargas, Aldo Damián (2015). "Marruecos y México: dos modelos de securitización migratoria en las fronteras de la globalización”. Ciencia UAT [en línea], 10 (1), julio-diciembre, pp. 47-55. Disponible en: https://www.redalyc.org/pdf/4419/441943134004.pdf (Consultado el 8 de febrero de 2021).

Rivas Castillo, Jaime Roberto (2008). Tejiendo redes frente al riesgo y la vulnerabilidad. Migrantes centroamericanos y organizaciones civiles de apoyo en Tapachula, Chiapas. Tesis para obtener el grado de Maestría en Antropología Social. Centro de Investigaciones y Estudios Superiores en Antropología Social, Sureste. Disponible en: http://repositorio.ciesas.edu. $\mathrm{mx} /$ handle/123456789/181?show=full (Consultado el 16 de mayo de 2021).

Rivas Castillo, Jaime Roberto (2011). "Víctimas nada más? Migrantes centroaméricanos en el Soconusco, Chiapas”. Nueva Antropología [en línea], 24 (74), pp. 9-38. Disponible en: http://rtmg.org/documents/426 (Consultado el 16 de mayo de 2021).

Sandoval García, Carlos (2015). No más muros. Exclusión y migración forzada en Centroamérica.

EntreDiversidades. Revista de Ciencias Sociales y Humanidades, Vol. 8, Núm. 2 (17), julio-diciembre 2021. Páginas: 167-190 ISSN-e: 2007-7610. https://doi.org/10.31644/ED.V8.N2.2021.A08 
San José, Costa Rica: Editorial Universidad de Costa Rica. Disponible en: http:// www.editorial.ucr.ac.cr/ciencias-sociales/item/2452-no-m\%C3\%A1s-murosexclusi\%C3\%B3n-y-migraci\%C3\%B3n-forzada-en-centroam\%C3\%A9rica.html (Consultado el 9 de febrero de 2021).

Schiavon, Jorge A. y Velázquez Flores, Rafael (2007). El 11 de septiembre y la relación MéxicoEstados Unidos: ¿Hacia la securitización de la agenda? Serie Documentos de Trabajo, Núm. 150. México, D.F., México: Centro de Investigación y Docencia Económicas. Versión posterior disponible en: http://www.revistaenfoques.cl/index.php/revista-uno/ article/view/217

Treviño Rangel, Javier (2016). "Organizaciones de la sociedad civil y la "securitización" de la migración internacional indocumentada en México”. Foro Internacional [en línea], 56 (2), pp. 253-291. doi: https://doi.org/10.24201/fi.v56i2.2316 (Consultado el 8 de febrero de 2021).

Treviño Rangel, Javier (2020). "Mercancías desechables: políticas de muerte y migración internacional en México", en Varela, Amarela (comp.). Necropolítica y migración en la frontera vertical mexicana. Un ejercicio de conocimiento situado. Ciudad de México, México: Instituto de Investigaciones Jurídicas, Universidad Nacional Autónoma de México, pp. 105-142.

Varela Huerta, Amarela (2017). "Las masacres de migrantes en San Fernando y Cadereyta: dos ejemplos de gubernamentalidad necropolítica". Íconos. Revista de Ciencias Sociales [en línea], Núm. 58, pp. 131-149. doi: https://doi.org/10.17141/iconos.58.2017.2486 (Consultado el 28 de enero de 2021).

Varela Huerta, Amarela (2019). "México, de 'frontera vertical' a 'país tapón'. Migrantes, deportados, desplazados internos, retornados y solicitantes de asilo en México". Iberoforum. Revista de Ciencias Sociales [en línea], 14 (27), pp. 49-76. Disponible en: https://iberoforum.ibero. mx/index.php/iberoforum/article/view/124 (Consultado el 28 de enero de 2021).

Vargas Carrasco, Felipe De Jesús (2018). "El vía crucis del migrante. Demandas, membresía e interlocutores”. Trace [en línea], Núm. 73, pp. 117-133. doi: http://dx.doi.org/10.22134/ trace.73.2018.88 (Consultado el 2 de febrero de 2021).

Zino Torrazza, Julio (2006). "Inmigración y prácticas sociales discriminatorias", en Bergalli, Roberto (coord.). Flujos migratorios y su (des)control. Puntos de vista pluridisciplinarios. Barcelona, España: Anthropos, pp. 25-42.

EntreDiversidades. Revista de Ciencias Sociales y Humanidades, Vol. 8, Núm. 2 (17), julio-diciembre 2021. Páginas: 167-190 ISSN-e: 2007-7610. https://doi.org/10.31644/ED.V8.N2.2021.A08 